\title{
Analyzing spike train similarity measures: the effects of bursts and silence
}

\author{
David Lyttle ${ }^{1 *}$, Jean-Marc Fellous ${ }^{2}$ \\ From Nineteenth Annual Computational Neuroscience Meeting: CNS*2010 \\ San Antonio, TX, USA. 24-30 July 2010
}

A fundamental issue in neuroscience research is that of quantifying the similarity or dissimilarity of patterns of neuronal activity, or "spike trains." Several approaches to solving this problem have been proposed, in particular, a variety of spike train similarity measures have been constructed [1-7]. Some of these quantitative measures of similarity are metrics in the strict mathematical sense of the word, and all of them can be thought of as attempts to define the intuitive notion of a "distance" between two spike trains. In constructing or choosing a similarity measure, one faces the question of what exactly it means for two trains to be considered similar (close) or dissimilar (far apart), and how this definition of similarity is incorporated into the measure. That choice may depend explicitly upon the nature of the neural system being investigating. In any case, one is faced with the problem of deciding exactly which features of a spike train are physiologically relevant and important for encoding information. Features of interest include neuronal firing rate, spike timing, bursts, or periods of inactivity that are correlated between neurons.

The existence of a wide range of possible mechanisms through which spike trains could be encoding information calls into question the idea that a single similarity measure is appropriate for all data sets or experimental conditions. It may be that the best choice of a similarity measure depends intimately upon the specific features of the spike data under analysis. To date, the extent to which different measures respond differently to various specific features of spike trains has for the most part not been explored, although a recent study [8] has compared a handful of these measures on the basis of their effectiveness in discriminating spike trains on the basis of firing rate, instantaneous firing rate and spike

\footnotetext{
* Correspondence: dlyttle@math.arizona.edu

'Program in Applied Mathematics, University of Arizona, Tucson, AZ 85721, USA
}

synchrony. In contrast, in the present study we propose a novel set of criteria along which to evaluate spike train similarity measures. In particular, we examine the sensitivity of the measures to periods of common silence and the presence and timing of bursts through a set of simple computational tests. We find that, of the measures we examined, only a few were sensitive to bursts, and only one displayed sensitivity to shared silence. None were sensitive to both bursts and silence. In light of this, we introduce a new measure designed specifically to detect and emphasize shared periods of silent inactivity, and evaluate this measure along the same criteria as the others. We find that this new measure, when combined in a natural way with a measure proposed by Schreiber et al., [5] is unique in its sensitivity to both bursts and shared periods of inactivity. Further work will involve subjecting this new measure to the sort of analysis conducted by others [8] to further elucidate its properties. Another promising avenue is to compare this new measure to others on the basis of clustering performance, as has been done with other measures [6].

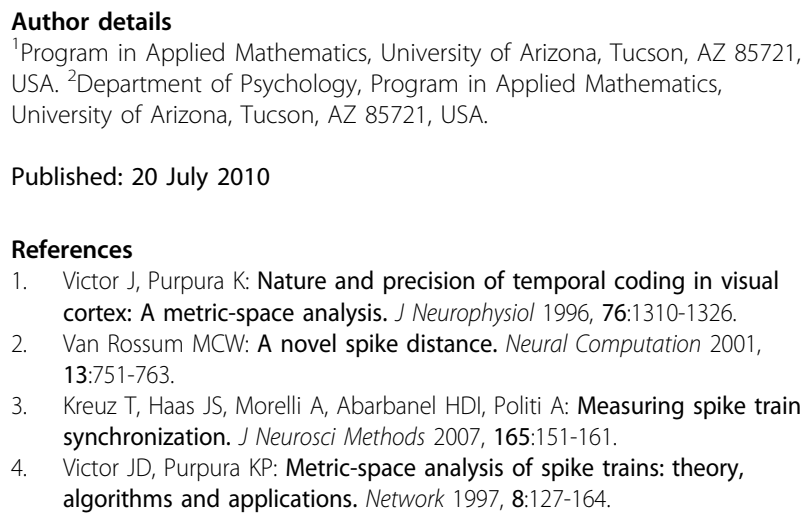

Published: 20 July 2010 
5. Schreiber S, Fellous JM, Whitmer D, Tiesinga P, Sejnowski TJ: A new correlation-based measure of spike timing reliability. Neurocomputing 2003, 52:925-931.

6. Kreuz T, Haas JS, Morelli A, Abarbanel HDI, Politi A: Measuring spike train synchrony. J Neurosci Methods 2007, 165:151-161.

7. Quian Quiroga R, Kreuz T, Grassberger P: Event synchronization: A simple and fast method to measure synchronicity and time delay patterns. Phys Rev E Stat Nonlin Soft Matter Phys 2002, 66:041904.

8. Paiva A, Park I, Principe J: A comparison of binless spike train measures. Neural Computing and Applications 2009, 18:1-22.

doi:10.1186/1471-2202-11-S1-P121

Cite this article as: Lyttle and Fellous: Analyzing spike train similarity measures: the effects of bursts and silence. BMC Neuroscience 2010

11(Suppl 1):P121.

Submit your next manuscript to BioMed Central and take full advantage of:

- Convenient online submission

- Thorough peer review

- No space constraints or color figure charges

- Immediate publication on acceptance

- Inclusion in PubMed, CAS, Scopus and Google Scholar

- Research which is freely available for redistribution

Submit your manuscript at www.biomedcentral.com/submit 